\title{
The plcR regulon is involved in the opportunistic properties of Bacillus thuringiensis and Bacillus cereus in mice and insects
}

\author{
Sylvie Salamitou, ${ }^{1,2}$ Françoise Ramisse, ${ }^{3}$ Michel Brehélin, ${ }^{4}$ \\ Denis Bourguet, ${ }^{2}$ Nathalie Gilois, ${ }^{2}$ Myriam Gominet, ${ }^{1}$ Eric Hernandez, ${ }^{5}$ \\ and Didier Lereclus ${ }^{1,2}$
}

\begin{abstract}
Author for correspondence: Didier Lereclus. Tel: +33 1456888 13. Fax: +3314568 8938 . e-mail: lereclus@pasteur.fr
\end{abstract}

1 Unité de Biochimie Microbienne, CNRS (URA2172), Institut Pasteur, 25 rue du Docteur Roux, 75724 Paris cedex, France

2 Unité de Lutte Biologique, INRA, La Minière, 78285 Guyancourt cedex, France

3 Centre d'Etudes du Bouchet, Laboratoire de Microbiologie, 91710 VertLe-Petit, France

4 Laboratoire de Pathologie Comparée, INRA-CNRS (URA 2209), Université Montpellier II, 34095 Montpellier, France

5 Laboratoire de Biologie, HIA Bégin, 94160 Saint Mandé, France

\begin{abstract}
Bacillus thuringiensis has been widely used for $\mathbf{4 0}$ years as a safe biopesticide for controlling agricultural pests and mosquitoes because it produces insecticidal crystal proteins. However, spores have also been shown to contribute to overall entomopathogenicity. Here, the opportunistic properties of acrystalliferous B. thuringiensis $\mathrm{Cry}^{-}$and Bacillus cereus strains were investigated in an insect species, Galleria mellonella, and in a mammal, BALB/c mice. In both animal models, the pathogenicity of the two bacterial species was similar. Mutant strains were constructed in which the plcR gene, encoding a pleiotropic regulator of extracellular factors, was disrupted. In larvae, coingestion of $10^{6}$ spores of the parental strain with a sublethal concentration of Cry1C toxin caused $70 \%$ mortality whereas only $7 \%$ mortality was recorded if spores of the $\Delta$ plcR mutant strain were used. In mice, nasal instillation of $10^{8}$ spores of the parental strain caused $100 \%$ mortality whereas instillation with the same number of $\Delta$ plcR strain spores caused much lower or no mortality. Similar effects were obtained if vegetative cells were used instead of spores. The cause of death is unknown and is unlikely to be due to actual growth of the bacteria in mice. The lesions caused by $B$. thuringiensis supernatant in infected mice suggested that haemolytic toxins were involved. The cytolytic properties of strains of $B$. thuringiensis and $B$. cereus, using sheep, horse and human erythrocytes and G. mellonella haemocytes, were therefore investigated. The level of cytolytic activity is highly reduced in $\Delta p / c R$ strains. Together, the results indicate that the pathogenicity of $B$. thuringiensis strain 407 and B. cereus strain ATCC 14579 is controlled by PIcR.
\end{abstract}

Keywords: Bacillus, cytolysin, haemolysin, insect pathogen, $p l c R$ regulon

\section{INTRODUCTION}

Bacillus thuringiensis and Bacillus cereus are sporeforming Gram-positive bacteria commonly found in soil and many other sources. In the light of genomic data, $B$. thuringiensis can be seen as a $B$. cereus that produces crystals (Carlson \& Kolstø, 1993; Helgason et al., 2000); the key characteristic of B. thuringiensis is the production of insecticidal crystalline inclusions during the stationary phase (Schnepf et al., 1998). Generally, the Cry toxins that constitute the crystal inclusion are sufficient to kill infected insect larvae. When ingested by susceptible insect larvae, these crystal proteins are dissolved and activated in the insect gut. They bind to specific receptors located on the midgut epithelial cells, forming transmembrane pores and causing cell lysis. This specific toxaemia may lead, by itself, to the death of the insect larvae. However, in some cases, $B$. thuringiensis and B. cereus spores have been shown to be involved in pathogenicity in insects (Dubois \& Dean, 1995; Johnson \& McGaughey, 1996; Li et al., 1987). It has been suggested that the toxaemic effect of the crystal proteins creates conditions favourable for the development of the bacteria in the gut of weakened insect larvae (Schnepf et al., 1998). The bacteria can then invade the haemocoel and cause septicaemia. B. cereus, 
although commonly regarded as a relatively nonpathogenic opportunist associated with diarrhoeal food poisoning, has been increasingly isolated from serious and sometimes fatal cases including non-gastrointestinal infections such as endocarditis, wound infections, pneumonia and endophthalmitis (Beecher et al., 1995a; Drobniewski, 1993; Miller et al., 1997).

B. thuringiensis and B. cereus cells produce several extracellular degradative enzymes such as phospholipases C, enterotoxins and haemolysins, which are putative virulence factors (Beecher et al., 1995a; Drobniewski, 1993). A transcriptional activator that positively regulates the expression of phospholipase $\mathrm{C}$ genes, during the late vegetative growth of $B$. thuringiensis cells, has been identified and named PlcR (Lereclus et al., 1996). This regulator governs the expression of a large regulon encoding extracellular proteins including degradative enzymes, cell-surface proteins and enterotoxins (Agaisse et al., 1999). Hence, $\mathrm{PlcR}$ appears to be a pleiotropic regulator of genes encoding extracellular factors potentially involved in pathogenicity. In this paper, we report experiments with two animal models (a lepidopteran insect, Galleria mellonella, and a mammal, $\mathrm{BALB} / \mathrm{c}$ mice) to evaluate the opportunistic properties of $B$. thuringiensis and $B$. cereus. In both models, the pathogenicity of $B$. thuringiensis and B. cereus was similar and was highly reduced or abolished by the disruption of the $p l c R$ gene.

\section{METHODS}

Bacterial strains and culture conditions. Escherichia coli $\mathrm{K}-12$ strain TG1 (Gibson, 1984) was used as intermediary host for the cloning experiments. The B. thuringiensis $407 \mathrm{Cry}^{-}$strain used throughout this study is an acrystalliferous mutant strain belonging to the thuringiensis subspecies (serotype 1) (Lereclus et al., 1989). The B. cereus strain was the reference strain ATCC 14579. For insect bioassays, spores of the various Bacillus species were obtained by culturing cells in HCT medium (Lecadet et al., 1980) at $30^{\circ} \mathrm{C}$ for $4 \mathrm{~d}$. Spores were harvested by centrifugation $(10410 \mathrm{~g}, 15 \mathrm{~min})$ and washed twice with sterile distilled water $(2 \times 100 \mathrm{ml})$. The spore pellets were resuspended in $10 \mathrm{ml}$ sterile distilled water. Spore preparations were heated for $20 \mathrm{~min}$ at $80^{\circ} \mathrm{C}$.

For nasal instillation in mice, the vegetative cells were prepared from cultures in Tryptic Soy Broth (Difco) at $37^{\circ} \mathrm{C}$. The cells were recovered after culture for $18 \mathrm{~h}$ (late stationary phase) by centrifugation at $7000 \mathrm{~g}$ for $15 \mathrm{~min}$. The pellets were washed and suspended in PBS (phosphate-buffered saline, $\mathrm{pH}$ $7 \cdot 2$; Sigma). Spore suspensions used for nasal instillation were prepared from a 10-d-old culture on agar medium containing

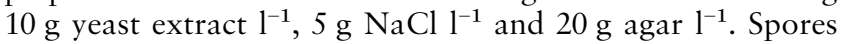
were washed and suspended in sterile water, and incubated for $1 \mathrm{~h}$ at $65^{\circ} \mathrm{C}$ to kill the vegetative forms.

Spores and vegetative cells were counted before bioassays by plating serial dilutions on LB agar plates. Spore preparations could be stored at $4{ }^{\circ} \mathrm{C}$ for $10 \mathrm{~d}$; vegetative cells were prepared for each experiment.

The B. thuringiensis $407 \mathrm{Cry}^{-} \Delta$ spo0A mutant strain has been described elsewhere (Lereclus et al., 1995). This strain is an asporogenic acrystalliferous mutant. pHTF3-1C, carrying the cry $1 \mathrm{C}$ gene fused to the $c r y 3 \mathrm{~A}$ promoter region, was intro- duced into this strain, resulting in the production of Cry1C crystals in a Spo- background (Sanchis et al., 1996). The resulting $407 \mathrm{Cry}^{-}[\Delta s p o 0 A$, pHTF3-1C] strain was designated $407 \mathrm{Cry}^{-}$0A-1C. Cry1C toxins were prepared from the 407 $\mathrm{Cry}^{-} 0 \mathrm{~A}-1 \mathrm{C}$ strain grown in $\mathrm{LB}$ medium at $30{ }^{\circ} \mathrm{C}$ for $4 \mathrm{~d}$. The culture was centrifuged at $10410 \mathrm{~g}$ for $20 \mathrm{~min}$ and the pellet was washed twice in sterile distilled water $(2 \times 100 \mathrm{ml})$. It was resuspended in $10 \mathrm{ml}$ sterile distilled water. The Cry1C crystal preparation was briefly sonicated before use. Crystal protein was determined with the Bio-Rad protein assay procedure (Bradford), using bovine serum albumin as the standard.

For evaluation of the cytolytic activity of the culture supernatants, B. thuringiensis strains were grown at $30^{\circ} \mathrm{C}$ in $\mathrm{LB}$ medium for the tests with insect haemocytes or in Tryptic Soy Broth (Difco) for the tests with human erythrocytes. The culture supernatants were recovered $2 \mathrm{~h}$ after the end of the exponential-growth phase. Cells were pelleted by centrifugation $(10410 \mathrm{~g}$ for $10 \mathrm{~min}$ ) and the supernatants were sterilized by filtration using filters with $0 \cdot 22 \mu \mathrm{m}$ pores (Sartorius).

In vivo experiments. G. mellonella eggs were hatched at $30{ }^{\circ} \mathrm{C}$ and the larvae reared on beeswax and pollen (Naturalim). Last instar larvae (150-350 mg) were force-fed using $0.5 \times 25 \mathrm{~mm}$ needles (Burkard Manufacturing) and a microinjector (Automatic Microapplicator; Burkard Manufacturing) with spore/ crystal suspensions in sterile water $(10 \mu$ l per larva). Thirty larvae were used for each dose. Infection of $G$. mellonella larvae (last instar) by intrahaemocoelic injection was performed as follows. Groups of 30 larvae were injected at the base of last proleg with $10 \mu \mathrm{l}$ spore preparation using the Burkard microinjector with a $1 \mathrm{ml}$ hypodermic syringe and $0.45 \times 12 \mathrm{~mm}$ needles (Terumo). After force-feeding and injection experiments, the larvae were kept individually in boxes containing beeswax and pollen at $25^{\circ} \mathrm{C}$. They were checked daily and casualties were recorded over $7 \mathrm{~d}$. For injection experiments, mortality data were analysed using the log-probit program of Raymond et al. (1993). This program tests the linearity of dose-mortality curves, provides lethal doses $\left(\mathrm{LD}_{50}\right)$ and the slope of each dose-mortality curve. Mortality curves were considered identical when their parallelism was not rejected at the 0.05 level and the $95 \%$ confidence limits of the susceptibility ratio included the value 1 . To count $B$. thuringiensis cells in the living and dead insects, 10 larvae were crushed and homogenized in $10 \mathrm{ml}$ sterile water; dilutions were plated onto LB agar plates containing appropriate antibiotics. The parental strain, B. thuringiensis $407 \mathrm{Cry}^{-}$, is resistant to oxacillin $\left(10 \mu \mathrm{g} \mathrm{ml}^{-1}\right)$ and the mutant strain, B. thuringiensis $407 \mathrm{Cry}^{-} \Delta p l c R$, is resistant to oxacillin and kanamycin $\left(250 \mu \mathrm{g} \mathrm{ml}^{-1}\right)$.

We used 5-week-old female BALB/c mice (Charles River) kept in a biosafety containment facility in groups of five, with sterile water and food. For each strain, groups of 5-10 mice were infected intranasally under slight ether anaesthesia with $50 \mu \mathrm{l}$ of the appropriate suspension. The spore or bacterial suspension was carefully deposited at the corner of the nostril. The mouse inhaled the inoculum naturally by breathing, so there was therefore no mechanical traumatism.

Construction of mutant strains. To obtain the $\Delta p l c R$ strains, the B1 insert cloned in pHT304 (Lereclus et al., 1996) was inserted (SmaI/HindIII) into the pKS vector. The resulting plasmid isolated from E. coli transformants was designated $\mathrm{pKS} \Omega \mathrm{B} 1$. The $\mathrm{Km}^{\mathrm{R}}$ cassette of pDG783, conferring resistance to kanamycin $\left(\mathrm{Km}, 250 \mu \mathrm{g} \mathrm{ml} \mathrm{m}^{-1}\right.$ ), was isolated as a $1.5 \mathrm{~kb}$ EcoRI fragment carrying the aphA3 gene from Enterococcus faecalis (Trieu-Cuot \& Courvalin, 1983). This $\mathrm{Km}^{\mathrm{R}}$ cassette 
was then inserted into pKS $\Omega \mathrm{B} 1$, between the internal EcoRI sites of $p l c R$, yielding $\mathrm{pKS} \Omega \mathrm{B} 1 \mathrm{Km}^{\mathrm{R}}$. The disrupted $p l c R$ gene was then inserted between the BamHI and HindIII sites of the thermosensitive plasmid pRN5101, conferring resistance

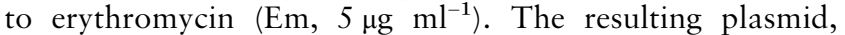
pRNB1 $\mathrm{Km}^{\mathrm{R}}$, was introduced into B. thuringiensis and $B$. cereus by electroporation (Lereclus et al., 1989) and the chromosomal wild-type copy of plcR was replaced by the disrupted copy as previously described (Lereclus et al., 1995). Mutant colonies had an $\mathrm{Em}^{\mathrm{s}}, \mathrm{Km}^{\mathrm{R}}$ phenotype. The genotype was checked by PCR.

Degradative enzyme activity measurements. Columbia medium agar plates (BioMérieux) containing either $5 \%$ horse blood or $5 \%$ sheep blood, and $5 \%$ human blood agar plates (Sanofi Pasteur) were used to evaluate the haemolytic activity of the B. thuringiensis and B. cereus strains. Tests for cytotoxic activity were performed as previously described (Ribeiro et al., 1999). Briefly, chilled 2-d-old last-instar larvae of $G$. mellonella were surface sterilized before collection of haemolymph in anticoagulant buffer $(62 \mathrm{mM} \mathrm{NaCl}, 100 \mathrm{mM}$ glucose, $10 \mathrm{mM}$ EDTA, $30 \mathrm{mM}$ trisodium citrate, $26 \mathrm{mM}$ citric acid, $\mathrm{pH} 4 \cdot 5)$. The haemolymph was centrifuged and the haemocyte pellet was rinsed and resuspended in PBS. Haemocyte suspension $(20 \mu \mathrm{l})$ was layered on heat-sterilized $\left(220^{\circ} \mathrm{C}, 2 \mathrm{~h}\right)$ coverslips and haemocytes were allowed to spread and to adhere to the glass for $15 \mathrm{~min}$ in a wet chamber at room temperature. The monolayers were rinsed, $20 \mu \mathrm{l}$ of the solution under study was added and the monolayers were incubated for $1 \mathrm{~h}$ at $23{ }^{\circ} \mathrm{C}$ for microscopy and counting of dead cells. Haemocyte mortality was checked by adding $2 \mu \mathrm{l}$ Trypan Blue dye $(0.4 \%$ in PBS) and incubating for a further 5 min.

\section{RESULTS AND DISCUSSION}

\section{Pathogenicity of $B$. thuringiensis and $B$. cereus in insects}

To assess the pathogenicity of $B$. thuringiensis and $B$. cereus against insects, spores were either fed to the larvae in association with the insecticidal toxin Cry1C or injected alone into the haemocoel. The lepidopteran species G. mellonella is a useful model because the larvae are susceptible to the ingestion of B. thuringiensis spore/crystal mixtures but only weakly susceptible to the ingestion of crystals alone (Li et al., 1987). To prevent the cross-contamination of crystals with spores, we used engineered $B$. thuringiensis strains that produce either Cry1C crystals and no spores (strain 407 0A-1C), or spores but no crystals (strain $407 \mathrm{Cry}^{-}$).

A clear pattern of synergism was observed in analysis of the force-feeding assays (Fig. 1). Very low mortality levels $(<10 \%)$ were obtained with crystals or spores alone. In contrast, mixing B. thuringiensis spores and crystals strongly increased mortality, demonstrating synergism $(70 \%$ mortality). Killing the spores by autoclaving before force-feeding them to G. mellonella abolished synergism (not shown), suggesting that either heat-labile toxic components are associated with the spores or the spores germinate. As co-ingested crystals and vegetative cells of $B$. thuringiensis were also synergistic (47\% mortality, not shown), the spores are almost certainly living and able to develop into veg-

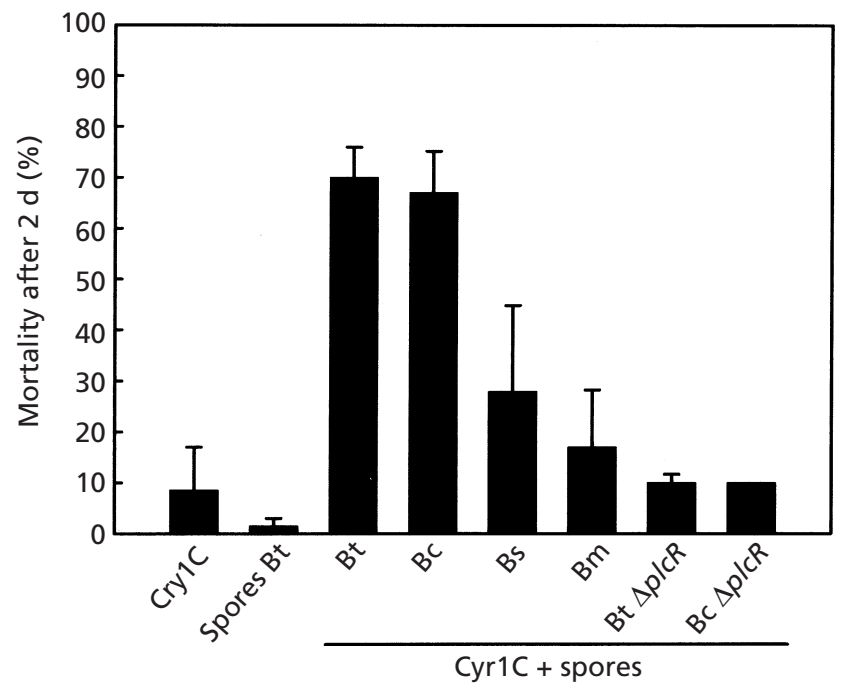

Fig. 1. Synergism of spores and crystals as an evaluation of pathogenicity in G. mellonella larvae. Cry1C crystals $(1 \mu \mathrm{g}$ per larva) were added in all assays except when $B$. thuringiensis spores alone were used as a control. Cry1C indicates Cry1C crystals without spores (control); Spores Bt, $10^{6} 407 \mathrm{Cry}^{-}$spores without crystals per larva (control). Bt, Bc, Bs and $\mathrm{Bm}$ indicate the results obtained when $10^{6}$ spores of $B$. thuringiensis 407 $C^{-}{ }^{-}, B$. cereus, $B$. subtilis and $B$. megaterium were used, respectively. Bt $\Delta p / c R$ and $\mathrm{Bc} \Delta p / c R$ indicate the results obtained with $10^{6}$ spores of the $B$. thuringiensis 407 Cry $^{-} \Delta p / c R$ and $B$. cereus $\triangle p / c R$ mutant strains, respectively. All experiments were repeated twice, except those with the $B$. cereus $\Delta p / c R$ strain (one assay). Bars indicate standard error.

etative cells. This is consistent with the increase in bacterial count observed on collection of the contents of the haemocoel from living larvae when, due to transit elimination, a decrease in spore count was expected (Fig. 2a).

We investigated whether synergism with Cry1C crystals could be achieved with any Bacillus species using a fixed dose of spores (Fig. 1). There was a significant difference in the synergism with Bacillus megaterium and Bacillus subtilis spores (Fisher's test; $P<0 \cdot 0001$ ). In contrast, the level of synergism with $B$. cereus spores was of the same order as that obtained with B. thuringiensis. This is consistent with the taxonomic identity of $B$. thuringiensis and $B$. cereus (Carlson \& Kolstø, 1993; Helgason et al., 2000). The two species have extensive genome identity, including a complete copy of the plcR gene (Agaisse et al., 1999; Økstad et al., 1999).

We assessed the extent to which the PlcR-regulated genes are involved in pathogenicity by evaluating the entomopathogenic properties of $B$. thuringiensis 407 $\mathrm{Cry}^{-} \Delta p l c R$ and B. cereus $\Delta p l c R$ mutant strains in in vivo experiments. Spores from these two mutant strains did not have a synergistic effect against the G. mellonella larvae (Fig. 1) : the lethality was similar to that of Cry1C crystals alone. On agar plates, the germination rate of the $407 \mathrm{Cry}^{-} \Delta p l c R$ strain did not appear to differ from that of the parental strain, thus excluding a major defect 


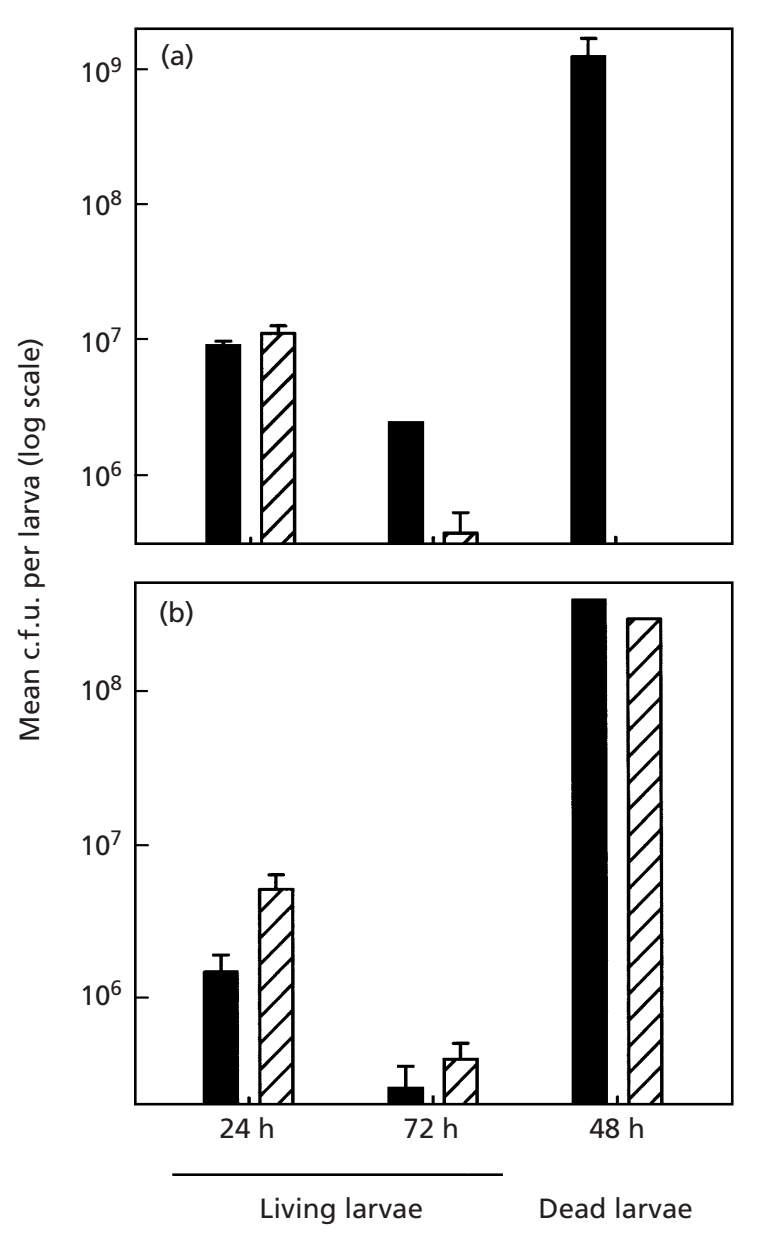

Fig. 2. Dynamics of infection in G. mellonella larvae. Cry $1 \mathrm{C}$ crystals $(1 \mu \mathrm{g}$ per larva) were added in all assays. (a) Monoinfection: $2 \times 10^{6} 407 \mathrm{Cry}^{-}$spores (Bt) or $2 \times 10^{6} 407 \mathrm{Cry}^{-} \Delta \mathrm{p} / \mathrm{cR}$ spores (Bt $\Delta p / c R$ ) were fed to the larvae. (b) Co-infection: $10^{6}$ spores $407 \mathrm{Cry}^{-}$strain and $10^{6}$ spores $407 \mathrm{Cry}^{-} \Delta$ plcR were fed to the larvae. $B$. thuringiensis cells were counted at various times after infection (24, 48 or 72 h) from living and dead larvae. Where standard error (bars) is not indicated, the results were obtained from the mean of a single pool of 10 larvae. Black bars, Bt wild-type; hatched bars, Bt $\Delta p / c R$.

in germination. This is consistent with the co-infection experiments (see below and Fig. 2a, b), showing that the $\Delta p l c R$ mutants are able to germinate in insect larvae.

The pathogenicity of the B. thuringiensis parental strain, $407 \mathrm{Cry}^{-}$, and of the $407 \mathrm{Cry}^{-} \Delta p l c R$ mutant was also assessed by introducing the spores into the larval haemocoel by injection. The mortality curves for the parental and mutant strains were not significantly different (parallelism not rejected: $\chi^{2}=0.68$, d.f. $=5$, $P>0.98$; the ratio of the $\mathrm{LD}_{50}$ included the value 1$)$. The $\mathrm{LD}_{50}$ (and the confidence intervals), determined $2 \mathrm{~d}$ after injection of the spores, were $1.7 \times 10^{4} \quad\left(8.4 \times 10^{3}-\right.$ $\left.3.7 \times 10^{4}\right)$ for the parental strain, $407 \mathrm{Cry}^{-}$, and $1.8 \times 10^{4}$ $\left(8.5 \times 10^{3}-4.1 \times 10^{4}\right)$ for the $407 \mathrm{Cry}^{-} \Delta p l c R$ mutant strain. In addition, mortality kinetics were similar for the two B. thuringiensis strains: in both cases, the larvae began to die $16 \mathrm{~h}$ after infection and mortality reached a plateau $2 \mathrm{~d}$ later. These results indicate that the $p l c R$ regulon is not required for pathogenicity if the spores are mechanically introduced into the haemocoel. Hence, $\mathrm{PlcR}$ appears to play a key role in the regulation of the synergistic properties of $B$. thuringiensis (and B. cereus) if spores enter the larvae via the digestive tract, suggesting a role in the early stages of infection (for example, by allowing the cells to gain access to the haemocoel from the gut).

\section{The role of the plcR regulon in the entomopathogenicity of $B$. thuringiensis}

PlcR-regulated genes encode proteins containing sequences similar to secretory signal peptides (Agaisse $e t$ al., 1999; Økstad et al., 1999). Thus, the $407 \mathrm{Cry}^{-} \Delta p l c R$ strain may be less able to cause opportunistic infections due to its inability to produce one or several of these secreted factors. Thus, the parental strain may provide the mutant with extracellular factors, enabling it to multiply in co-infected larvae. To test this hypothesis, we first compared the fate of the B. thuringiensis parental strain, $407 \mathrm{Cry}^{-}$, and of the $407 \mathrm{Cry}^{-} \Delta p l c R$ mutant strain in G. mellonella larvae, following mono-infection experiments with spore/crystal preparations (Fig. 2a). At $24 \mathrm{~h}$ after infection, the two strains performed similarly with bacterial counts of about $9 \times 10^{6}$ c.f.u. larva $^{-1}$ and $10^{7}$ c.f.u. larva ${ }^{-1}$, respectively. Two days later, substantial multiplication $\left(10^{9}\right.$ c.f.u. $\left.\operatorname{larva}^{-1}\right)$ had occurred in dead larvae infected with the parental strain. No dead larvae were obtained from the insects infected with the $\Delta p l c R$ mutant. After $72 \mathrm{~h}, 2.4 \times 10^{6}$ c.f.u. larva $^{-1}$ were isolated from living larvae infected with the parental strain and $3.7 \times 10^{5}$ c.f.u. larva ${ }^{-1}$ were isolated from larvae infected with $407 \mathrm{Cry}^{-} \Delta p l c R$ spores. This suggests that bacterial multiplication essentially occurs in the dead larvae. Thus, both the wild-type and mutant cells are slowly eliminated from larvae surviving the infection (compare bacterial counts from living larvae at $24 \mathrm{~h}$ and $72 \mathrm{~h}$, in Fig. 2a).

We next assessed the multiplication of the parental and mutant strains following co-infection with spore/crystal preparations. Larvae were fed with a $50 \%$ initial ratio of the two types of spores (Fig. 2b). At $24 \mathrm{~h}$ after ingestion, $5 \cdot 1 \times 10^{6}$ of the recovered c.f.u. were of the $407 \mathrm{Cry}^{-}$ $\Delta p l c R$ type and $1.5 \times 10^{6}$ were of the $407 \mathrm{Cry}^{-}$type. The ratio $(77 \%$ versus $23 \%)$ is significantly different from the expected $50 \%$ ratio (Student's $t$-test $P<0 \cdot 01$ ). This may indicate that the $\Delta p l c R$ mutant has a selective advantage during the first few hours of infection. The ratio significantly decreased over time (one-way ANOva; $P=0.0073)$ and similar amounts of both strains were recovered from dead larvae at $48 \mathrm{~h}$ and from living larvae at $72 \mathrm{~h}$. These results show that the parental $B$. thuringiensis $407 \mathrm{Cry}^{-}$strain may provide extracellular factors enabling the $\Delta p l c R$ mutant to multiply in the infected larvae. Thus, the results for mono- and coinfections suggest two possible roles for PlcR: (1) the $p l c R$ regulon may be required to cause the death of the larvae so that the bacterial can multiply, or, conversely, (2) the $p l c R$ regulon may be required to create favourable 

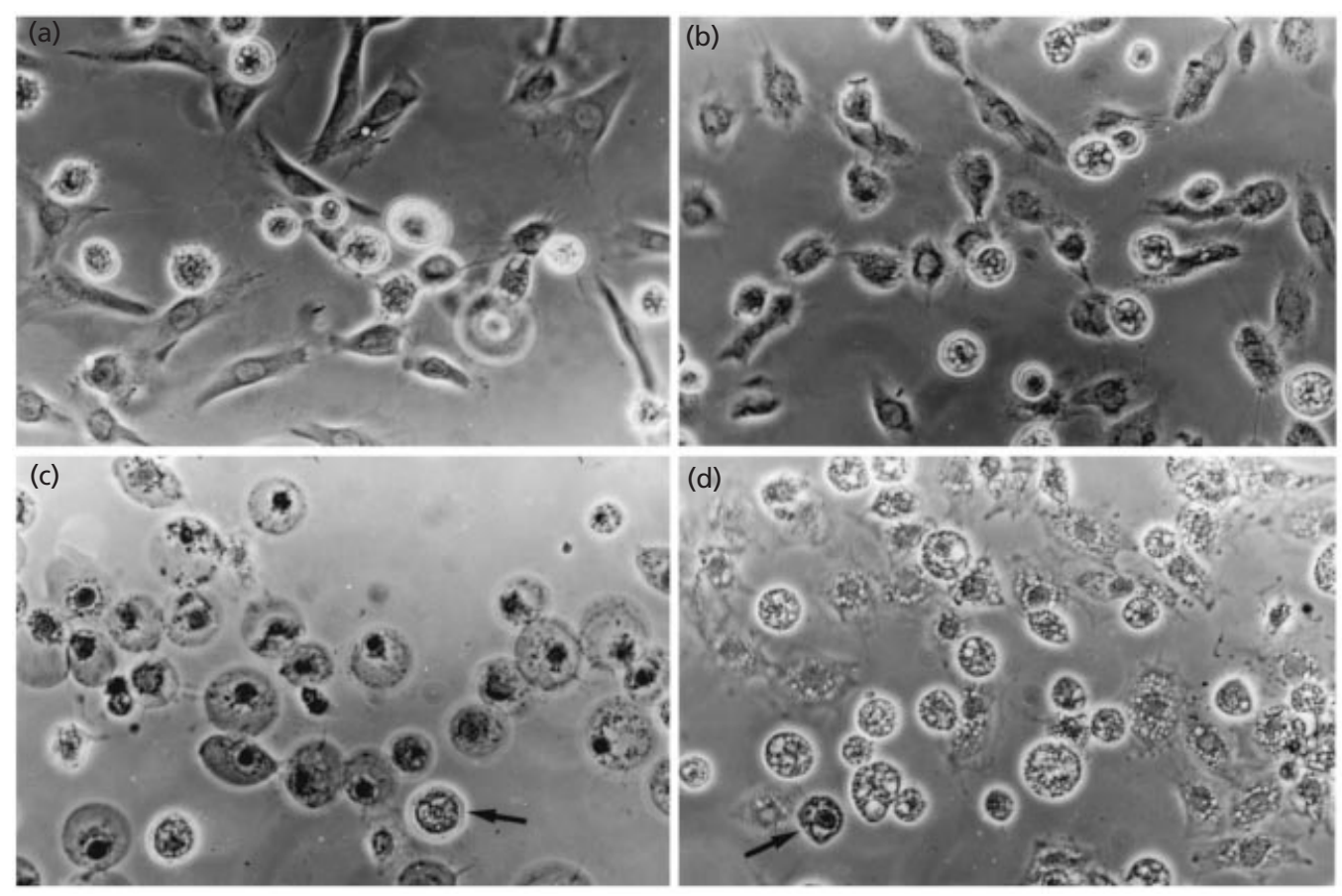

Fig. 3. Cytolytic activity of culture supernatants on G. mellonella haemocytes. (a) Sterile LB (control). Note the shape of plasmatocytes, which look like fibroblasts. The refractive rounded cells are granular haemocytes I. (b) B. subtilis supernatant. (c) $407 \mathrm{Cry}^{-}$supernatant. Most haemocytes are dead, swollen cells stained with Trypan Blue (dark nucleus). The arrow indicates a live granular haemocyte I. Plasmatocytes have lost their fibroblastic shape. (d) $407 \mathrm{Cry}^{-} \Delta \mathrm{p} / c R$ supernatant. Dead cells are very few in number (arrow). The haemocytes of both types show numerous small rounded vacuoles (compare with a and b).

conditions for bacterial multiplication, resulting in the death of the larvae by septicaemia.

\section{Cytotoxic and haemolytic activities are controlled by PICR}

Previous studies have indicated a possible correlation between phospholipase activity and the entomopathogenic properties of B. thuringiensis (Heimpel, 1955; Krieg, 1971; Stephens, 1952). Two phosphatidylcholine esterases are known to be encoded by PlcRregulated genes (Agaisse et al., 1999). They are phospholipase $\mathrm{C}$ and sphingomyelinase, which together form cereolysin AB (Gilmore et al., 1989). We checked that the $407 \mathrm{Cry}^{-} \Delta p l c R$ strain did not form a halo on lecithin-agar plates, consistent with the genetic data (results not shown). In addition, the gene encoding the haemolytic $\mathrm{HblC}$ component of the $\mathrm{Hbl}$ enterotoxin of $B$. thuringiensis and B. cereus is also regulated by $\mathrm{PlcR}$ (Agaisse et al., 1999; Økstad et al., 1999). As HblC is enterotoxigenic and haemolytic (Lindbäck et al., 1999), and phospholipases $\mathrm{C}$ are known to degrade the phospholipid constituents of cell membranes, we investigated the activity of culture supernatants from the 407 $\mathrm{Cry}^{-}$parental strain and from the $407 \mathrm{Cry}^{-} \Delta p l c R$ mutant strain against $G$. mellonella haemocytes.

Four haemocyte types are present in the haemolymph of G. mellonella larvae. Two of these cell types (Fig. 3a and $3 \mathrm{~b}$ ), plasmatocytes $(\mathrm{Pl})$ and granular haemocytes 1
(GH1) (Brehélin \& Zachary, 1986), are directly involved in defence reactions such as phagocytosis. They account for more than $80 \%$ of the total haemocyte population. The supernatant of the parental $407 \mathrm{Cry}^{-}$strain was strongly cytolytic to Pl and GH1 (Fig. 3c). Both cell types lost their shape and were stained with Trypan Blue, indicating cell death on a large scale. The supernatant of the $407 \mathrm{Cry}^{-} \Delta p l c R$ mutant strain had a different activity: cells were clearly not killed but extensive vacuole formation was observed (Fig. 3d). There was a highly significant difference in the number of dead cells between these two haemocyte preparations (Student's $t$ test; $\left.P<10^{-17}\right)$. Indeed, $99 \cdot 0 \%$ of the cells were dead after incubation with supernatant from the parental strain, $407 \mathrm{Cry}^{-}$, whereas only $5.3 \%$ of cells were dead after treatment with a supernatant from the $407 \mathrm{Cry}^{-}$ $\Delta p l c R$ mutant. The vacuole formation observed with the supernatant of the $407 \mathrm{Cry}^{-} \Delta p l c R$ mutant was not dependent on PlcR-regulated functions and may have been due to other compounds, such as the B. cereus emetic toxins, which are known to cause vacuole formation in eukaryotic cells (Agata et al., 1995). In contrast, sterile LB and the supernatant of a B. subtilis strain, used as controls, had no cytolytic effect on $G$. mellonella haemocytes (Fig. $3 \mathrm{a}$ and $3 \mathrm{~b}$ ).

The effect of plcR disruption was also tested on agar plates containing sheep, human or horse erythrocytes. $B$. thuringiensis $407 \mathrm{Cry}^{-}$and B. cereus grown on sheepblood agar produced intense haloes of degradative 
Table 1. Opportunistic properties of $B$. thuringiensis and $B$. cereus in mice

Percentage mouse mortality (number of dead mice/number of infected mice) at $24 \mathrm{~h}$ after nasal instillation with spores or vegetative cells of wild-type and $\Delta p l c R$ Bacillus strains. NT, not tested.

\begin{tabular}{|c|c|c|c|c|c|}
\hline Dose & $\begin{array}{c}\text { B. thuringiensis } 407 \\
\text { Cry }^{-}\end{array}$ & $\begin{array}{c}\text { B. thuringiensis } 407 \\
\text { Cry }^{-} \Delta \text { plcR }\end{array}$ & B. cereus ATCC 14579 & $\begin{array}{c}\text { B. cereus ATCC } 14579 \\
\Delta p l c R\end{array}$ & B. anthracis Sterne \\
\hline \multicolumn{6}{|c|}{ Spores per mouse } \\
\hline $10^{8}$ & $100(20 / 20)$ & $5(1 / 20)$ & $100(10 / 10)$ & $100(10 / 10)$ & $0(0 / 10)$ \\
\hline $5 \times 10^{7}$ & $31(11 / 35)$ & $0(0 / 10)$ & $90(9 / 10)$ & $22(2 / 9)$ & $0(0 / 10)$ \\
\hline $10^{7}$ & $0(0 / 25)$ & $0(0 / 5)$ & $90(9 / 10)$ & $0(0 / 10)$ & $0(0 / 5)$ \\
\hline \multicolumn{6}{|c|}{ Vegetative cells per mouse } \\
\hline $10^{8}$ & $100(10 / 10)$ & $0(0 / 10)$ & NT & NT & NT \\
\hline $2 \times 10^{7}$ & $100(5 / 5)$ & NT & NT & NT & NT \\
\hline $6 \times 10^{6}$ & NT & NT & $100(6 / 6)$ & $0(0 / 5)$ & $0(0 / 5)$ \\
\hline
\end{tabular}

activity (not shown). Similar results were obtained with colonies grown on human-blood agar and if culture supernatants, harvested $2 \mathrm{~h}$ after the end of the exponential-growth phase, were loaded on humanblood agar (not shown). On sheep-blood agar, a complex ring pattern was visible after a $36 \mathrm{~h}$ incubation. In contrast, colonies grown on horse-blood agar gave a simple faint halo. Therefore, various haemolytic components with different host specificities are probably involved in the formation of this pattern. The disruption of $p l c R$ markedly decreased activity on sheep- and human-blood agar plates for both the $407 \mathrm{Cry}^{-}$and $B$. cereus strains, but activity was not completely abolished for B. cereus (not shown). No such effect was observed with horse-blood agar plates. It has been shown that the $\mathrm{HblC}$ component of $B$. cereus is partly responsible for the haemolytic activity against sheep erythrocytes, but not against human erythrocytes (Callegan et al., 1999; Lindbäck et al., 1999). Thus, the specific activity of $B$. thuringiensis and $B$. cereus against human erythrocytes is probably due to the cereolysin AB component, which is known to cause the haemolysis of human erythrocytes (Gilmore et al., 1989).

\section{The opportunistic properties of $B$. thuringiensis and $B$. cereus in mice}

Hernandez et al. $(1998,1999)$ recently showed that some $B$. thuringiensis strains are pathogenic to mice by nasal instillation. We first determined whether the $B$. thuringiensis $407 \mathrm{Cry}^{-}$strain (subspecies thuringiensis) and $B$. cereus ATCC 14579 belonged to this group. Nasal instillation of $10^{8}$ or $5 \times 10^{7}$ spores of the $407 \mathrm{Cry}^{-}$ strain and of the $B$. cereus strain per mouse rapidly resulted in high mortality rates (Table 1 ). Mice died within $24 \mathrm{~h}$, with syndromes similar to those described for the B. thuringiensis strain konkukian (Hernandez et al., 1999). However, instillation of $10^{7}$ spores per mouse in the same volume $(50 \mu \mathrm{l})$ resulted in no deaths with 407 $\mathrm{Cry}^{-}$spores and a high mortality rate with the $B$. cereus strain, which suggests that the two strains differ in pathogenicity. Similar assays were performed with the Bacillus anthracis vaccine strain, Sterne, which lacks the virulence plasmid, pXO2. B. anthracis is a member of the $B$. cereus group, in which $p l c R$ is present in a truncated inactive form (Agaisse et al., 1999). B. anthracis Sterne, instilled at the same concentration, did not kill mice (Table 1 ). This indicates the existence in $B$. thuringiensis and $B$. cereus of specific opportunistic traits, not functional in a $\mathrm{pX02^{- }}$ strain of $B$. anthracis (i.e. the $p l c R$ regulon). B. thuringiensis vegetative forms instilled in mice at a dose of $10^{8}$ or $2 \times 10^{7}$ cells per mouse caused $100 \%$ mortality within 4-6 h, with haemorrhagic symptoms (nose bleeding and lungs clearly haemorrhagic on autopsy).

The properties of the $407 \mathrm{Cry}^{-} \Delta p l c R$ and B. cereus $\Delta p l c R$ strains were also assessed. Instillation of $10^{8}$ or $5 \times 10^{7}$ spores or vegetative cells per mouse of the 407 $\mathrm{Cry}^{-} \Delta p l c R$ mutant strain caused few or no deaths. The $B$. cereus $\Delta p l c R$ strain killed mice, but was less lethal than the parental strain (Table 1 ). This suggests that $B$. cereus strain ATCC 14579 possesses additional factors, not regulated by $\mathrm{PlcR}$, which may potentiate its opportunistic properties.

\section{Conclusions}

These results show that both $B$. thuringiensis and $B$. cereus possess opportunistic properties that may lead to rapid death of the host animals if large doses of vegetative or sporulated cells are used. The cause of death is unknown, and, in mice, it is unlikely to be due to the growth of the bacteria. However, as previously described (Hernandez et al., 1999), the syndromes observed in infected mice suggest that haemolysin production may be involved in death. These opportunistic properties have been lost (or highly reduced) in the $\Delta p l c R$ mutants of the B. thuringiensis and B. cereus strains used in this study, and they are also absent from a $B$. anthracis vaccine strain known to be defective in PlcR activity (Agaisse et al., 1999). These results suggest that pathogenesis in mice and insects requires common 
extracellular factors that depend on the plcR regulon. Thus, PlcR-regulated genes, such as those encoding the enterotoxins $\mathrm{Hbl}$ (Beecher et al., 1995b) and Nhe (Granum et al., 1999; Lund \& Granum, 1997), the phospholipase PI-PLC (Kuppe et al., 1989; Lechner et al., 1989) and the cereolysin AB component (Gilmore et al., 1989), may be responsible for pathogenicity. These four genes were found in the B. thuringiensis 407 and $B$. cereus ATCC 14579 strains used in this study (Agaisse et al., 1999; Økstad et al., 1999).

Here we show that in specific infection conditions, mammals may act as alternative hosts for insect pathogens. This is reminiscent of the multi-host system of the opportunistic bacterium Pseudomonas aeruginosa (Finlay, 1999; Jander et al., 2000; Rahme et al., 1997; Tan et al., 1999). Similarly, the B. thuringiensis/ insect pathogenesis model can be used to determine the factors involved in the opportunistic properties of bacilli.

In practical terms, these results clearly show that $B$. thuringiensis and B. cereus are opportunistic pathogens. As with B. cereus, B. thuringiensis strains produce various food poisoning toxins (Granum \& Lund, 1997) and a $B$. thuringiensis strain has been found associated with an outbreak of food poisoning (Jackson et al., 1995). However, by comparison with chemical pesticides, B. thuringiensis is generally recognized as a safe product and there is no evidence to suggest that its use for insect control should be reduced. Nevertheless, more detailed knowledge of the pathogenicity of each commercial strain may be required to improve the safety of $B$. thuringiensis-based biopesticides. It is therefore important to identify the PlcR-regulated functions specifically responsible for the opportunistic properties of B. thuringiensis and B. cereus.

\section{ACKNOWLEDGEMENTS}

We thank Georges Rapoport, in whose laboratory part of this work was conducted. We wish to thank Alain Givaudan and Michel Gohar for their valuable help. We are greatly indebted to Christophe Buisson and Alain Leréec for rearing the insects. We acknowledge Julie Sappa for English correction. This work was supported by an INRA grant (AIP Microbiologie).

\section{REFERENCES}

Agaisse, H., Gominet, M., Økstad, O. A., Kolstø, A. B. \& Lereclus, D. (1999). PlcR is a pleiotropic regulator of extracellular virulence factor gene expression in Bacillus thuringiensis. Mol Microbiol 32, 1043-1053.

Agata, N., Ohta, M., Mori, M. \& Isobe, M. (1995). A novel dodecadepsipeptide, cereulide, is an emetic toxin of Bacillus cereus. FEMS Microbiol Lett 129, 17-20.

Beecher, D. J., Pulido, J. S., Barney, N. P. \& Wong, A. C. (1995a). Extracellular virulence factors in Bacillus cereus endophthalmitis: methods and implication of involvement of hemolysin BL. Infect Immun 63, 632-639.

Beecher, D. J., Schoeni, J. L. \& Wong, A. C. (1995b). Enterotoxic activity of hemolysin BL from Bacillus cereus. Infect Immun 63, $4423-4428$.
Brehélin, M. \& Zachary, D. (1986). Insect haemocytes: a new classification to rule out the controversy. In Immunity in Invertebrates, pp. 36-48. Edited by M. Brehélin. Berlin \& Heidelberg: Springer.

Callegan, M. C., Jett, B. D., Hancock, L. E. \& Gilmore, M. S. (1999). Role of hemolysin BL in the pathogenesis of extraintestinal Bacillus cereus infection assessed in an endophthalmitis model. Infect Immun 67, 3357-3366.

Carlson, C. R. \& Kolstø, A.-B. (1993). A complete physical map of a Bacillus thuringiensis chromosome. J Bacteriol 175, 1053-1060.

Drobniewski, F. A. (1993). Bacillus cereus and related species. Clin Microbiol Rev 6, 324-338.

Dubois, N. R. \& Dean, D. H. (1995). Synergism between Cry1A insecticidal crystal proteins and spores of Bacillus thuringiensis, other bacterial spores and vegetative cells against Lymantria dispar (Lepidoptera: Lymantriidae) larvae. Environ Entomol 24, 1741-1747.

Finlay, B. B. (1999). Bacterial disease in diverse hosts. Cell 96, 315-318.

Gibson, T. J. (1984). Studies on the Epstein-Barr virus genome. $\mathrm{PhD}$ thesis, University of Cambridge.

Gilmore, M. S., Cruz-Rodz, A. M., Leimeister-Wächter, M., Kreft, J. \& Goebel, W. (1989). A Bacillus cereus cytolytic determinant, cereolysin $\mathrm{AB}$, which comprises the phospholipase $\mathrm{C}$ and sphingomyelinase genes: nucleotide sequence and genetic linkage. J Bacteriol 171, 744-753.

Granum, P. E. \& Lund, T. (1997). Bacillus cereus and its food poisoning toxins. FEMS Microbiol Lett 157, 223-228.

Granum, P. E., O'Sullivan, K. \& Lund, T. (1999). The sequence of the non-haemolytic enterotoxin operon from Bacillus cereus. FEMS Microbiol Lett 177, 225-229.

Heimpel, A. M. (1955). Investigations of the mode of action of strains of Bacillus cereus Fr. and Fr. pathogenic for the larch sawfly, Pristiphora erichsonii (Htg). Can J Zool 33, 311-326.

Helgason, E., Økstad, O. A., Caugant, D. A., Johansen, H. A., Fouet, A., Mock, M., Hegna, I. \& Kolstø, A. B. (2000). Bacillus anthracis, Bacillus cereus, and Bacillus thuringiensis - one species on the basis of genetic evidence. Appl Environ Microbiol 66, 2627-2630.

Hernandez, E., Ramisse, F., Ducoureau, J. P., Cruel, T. \& Cavallo, J. D. (1998). Bacillus thuringiensis subsp. konkukian (serotype H34) superinfection: case report and experimental evidence of pathogenicity in immunosuppressed mice. J Clin Microbiol 36, 2138-2139.

Hernandez, E., Ramisse, F., Cruel, T., le Vagueresse, R. \& Cavallo, J. D. (1999). Bacillus thuringiensis serotype H34 isolated from human and insecticidal strains serotypes 3a3b and H14 can lead to death of immunocompetent mice after pulmonary infection. FEMS Immunol Med Microbiol 24, 43-47.

Jackson, S. G., Goodbrand, R. B., Ahmed, R. \& Kasatiya, S. (1995). Bacillus cereus and Bacillus thuringiensis isolated in a gastroenteritis outbreak investigation. Lett Appl Microbiol 21, 103-105.

Jander, G., Rahme, L. G. \& Ausubel, F. M. (2000). Positive correlation between virulence of Pseudomonas aeruginosa mutants in mice and insects. J Bacteriol 182, 3843-3845.

Johnson, D. E. \& McGaughey, W. H. (1996). Contribution of Bacillus thuringiensis spores to toxicity of purified Cry proteins towards Indianmeal moth larvae. Curr Microbiol 33, 54-59.

Krieg, A. (1971). Is the potential pathogenicity of bacilli for insects related to production of $\alpha$-exotoxin. J Invertebr Pathol 18, $425-426$. 
Kuppe, A., Evans, L. M., McMillen, D. A. \& Griffith, O. H. (1989). Phosphatidylinositol-specific phospholipase $\mathrm{C}$ of Bacillus cereus: cloning, sequencing, and relationship to other phospholipases. $J$ Bacteriol 171, 6077-6083.

Lecadet, M. M., Blondel, M. O. \& Ribier, J. (1980). Generalized transduction in Bacillus thuringiensis var. berliner 1715, using bacteriophage CP54 Ber. J Gen Microbiol 121, 203-212.

Lechner, M., Kupke, T., Stefanovic, S. \& Götz, F. (1989). Molecular characterization and sequence of phosphatidylinositol-specific phospholipase C of Bacillus thuringiensis. Mol Micobiol 3, 621-626.

Lereclus, D., Arantes, O., Chaufaux, J. \& Lecadet, M.-M. (1989). Transformation and expression of a cloned $\delta$-endotoxin gene in Bacillus thuringiensis. FEMS Microbiol Lett 60, 211-217.

Lereclus, D., Agaisse, H., Gominet, M. \& Chaufaux, J. (1995). Overproduction of encapsulated insecticidal crystal proteins in a Bacillus thuringiensis spo0A mutant. Bio/Technology 13, 67-71.

Lereclus, D., Agaisse, H., Gominet, M., Salamitou, S. \& Sanchis, V. (1996). Identification of a Bacillus thuringiensis gene that positively regulates transcription of the phosphatidylinositol-specific phospholipase $\mathrm{C}$ gene at the onset of the stationary phase. $J$ Bacteriol 178, 2749-2756.

Li, R. S., Jarrett, P. \& Burges, H. D. (1987). Importance of spores, crystals, and $\delta$-endotoxins in the pathogenicity of different varieties of Bacillus thuringiensis in Galleria mellonella and Pieris brassicae. J Invertebr Pathol 50, 277-284.

Lindbäck, T., Økstad, O. A., Rishovd, A. L. \& Kolstø, A. B. (1999). Insertional inactivation of $\mathrm{bblC}$ encoding the $\mathrm{L} 2$ component of Bacillus cereus ATCC 14579 haemolysin BL strongly reduces enterotoxigenic activity, but not the haemolytic activity against human erythrocytes. Microbiology 145, 3139-3146.

Lund, T. \& Granum, P. E. (1997). Comparison of biological effect of the two different enterotoxin complexes isolated from three different strains of Bacillus cereus. Microbiology 143, 3329-3336.

Miller, J. M., Hair, J. G., Hebert, M., Hebert, L., Roberts, F. J., Jr \& Weyant, R. S. (1997). Fulminating bacteremia and pneumonia due to Bacillus cereus. J Clin Microbiol 35, 504-507.
Økstad, O. A., Gominet, M., Purnelle, B., Rose, M., Lereclus, D. \& Kolstø, A.-B. (1999). Sequence analysis of three Bacillus cereus loci under PlcR virulence gene regulator control. Microbiology 145, 3129-3138.

Rahme, L. G., Tan, M. W., Le, L., Wong, S. M., Tompkins, R. G., Calderwood, S. B. \& Ausubel, F. M. (1997). Use of model plant hosts to identify Pseudomonas aeruginosa virulence factors. Proc Natl Acad Sci U S A 94, 13245-13250.

Raymond, M., Prato, G. \& Ratsira, D. (1993). PROBIT analysis of mortality assays displaying quantal response. Praxème SARL, St Georges d'Orques, France.

Ribeiro, C., Duvic, B., Oliveira, P., Givaudan, A., Pahla, F., Simoes, N. \& Brehélin, M. (1999). Insect immunity: effects of factors produced by a nematobacterial complex on immunocompetent cells. J Insect Physiol 45, 677-685.

Sanchis, V., Agaisse, H., Chaufaux, J. \& Lereclus, D. (1996). Construction of new insecticidal Bacillus thuringiensis recombinant strains by using the sporulation non-dependent expression system of cryIIIA and a site specific recombination vector. $J$ Biotechnol 48, 81-96.

Schnepf, E., Crickmore, N., Van Rie, J., Lereclus, D., Baum, J., Feitelson, J., Zeigler, D. R. \& Dean, D. H. (1998). Bacillus thuringiensis and its pesticidal crystal proteins. Microbiol Mol Biol Rev 62, 775-806.

Stephens, J. M. (1952). Disease in codling moth larvae produced by several strains of Bacillus cereus. Can J Zool 30, 30-40.

Tan, M. W., Rahme, L. G., Sternberg, J. A., Tompkins, R. G. \& Ausubel, F. M. (1999). Pseudomonas aeruginosa killing of Caenorhabditis elegans used to identify $P$. aeruginosa virulence factors. Proc Natl Acad Sci U S A 96, 2408-2413.

Trieu-Cuot, P. \& Courvalin, P. (1983). Nucleotide sequence of the Streptococcus faecalis plasmid gene encoding the $3^{\prime} 5^{\prime}$-aminoglycoside phosphotransferase type III. Gene 23, 331-341.

Received 26 May 2000; revised 28 July 2000; accepted 1 August 2000. 